Article

\title{
Functional Needs, Emotions, and Perceptions of Coffee Consumers and Non-Consumers
}

\author{
Antonella Samoggia *(1), Margherita Del Prete and Chiara Argenti \\ Department of Agricultural and Food Sciences and Technologies, University of Bologna, 40126 Bologna, Italy; \\ margherita.delprete5@unibo.it (M.D.P.); info@chiaraargenti.it (C.A.) \\ * Correspondence: antonella.samoggia@unibo.it
}

Received: 18 May 2020; Accepted: 13 July 2020; Published: 15 July 2020

\begin{abstract}
Coffee is one of the most consumed beverages worldwide. Over the last decades coffee has become a specialty product. Drinking a coffee beverage entails several mixed factors, such as pleasure, experience, lifestyle, and social status. It can also provide an emotional pick-up, both mentally and physically. Only a few studies have explored the motives and emotions of coffee consumption and not consumption. There is limited understanding of consumers' emotional approach towards coffee, and what influences a positive and negative inclination towards coffee consumption. This research fills the current research gaps by addressing three main questions: (i) What are the emotions and habits of coffee consumption? (ii) What are the motives of coffee consumption and non-consumption? and (iii) How relevant is the coffee health impact perception of consuming or not consuming coffee? The research activities include 467 face-to-face interviews with consumers. Interviews are performed in two different countries, Italy and Portugal. Data elaboration includes a principal component analysis carried out to identify latent factors on motives and emotions of consumption in both national groups, and to explore the relationship between the main emotions and consumers' habits and socio-economic characteristics. Results support that consumers have positive emotions from coffee consumption. Perceived emotions are energy, satisfaction, and pleasure. Non-consumption is mainly driven by taste and fear of coffee's health impacts. There are limited differences in the countries analysed. Socio-economic characteristics limitedly influence perceived emotions and consumption motives. To conclude, consumers are increasingly interested in new coffee products. Understanding the functional and emotional factors of coffee consumption contributes to supporting new coffee product development and commercialisation.
\end{abstract}

Keywords: coffee; emotions; sustainability; health; consumer; perception; motives; non-consumption; food

\section{Introduction}

Coffee consumption has increased worldwide in the last 20 years. Global coffee consumption reached 166.06 million bags in 2019/2020, an increase of $0.5 \%$ on 2018/2019 [1]. Among the major coffee producers, the highest consumption growth was recorded in Vietnam (annual average rate of $+10 \%$ ) [2], with a Compound Annual Growth Rate (CAGR) of $+6.5 \%$ from 2016/17 to 2019/20. Among the biggest coffee importers, the European Union and the Unites States had a CAGR of $+1.2 \%$ and $+2.4 \%$, respectively, from 2017 to 2020 [3]. Furthermore, China (annual average growth rate of $+12 \%$ ) [2] is becoming the world's most promising market for coffee growers and international coffee chains [2].

In the last decades coffee has become a specialty and high-quality standard product. Coffee consumption is a moment of pleasure and part of a lifestyle [4-7]. The evolution coffee has faced is commonly recognized as the "three waves of consumption" [6]. The first wave, at the end of the 
nineteenth century, consisted of converting coffee into an industrial good, mainly managed by Brazil and the United States coffee industry. In the 1990s, with the second wave movement, coffee became a specialty beverage, setting a new consumption era. Quality, flavour, ethics were the main drivers of consumption. With the new century, the third wave of coffee consumption initiated, with increased attention towards high-quality coffee. The act of drinking a coffee beverage has evolved. It includes several mixed factors, such as pleasure, experience, lifestyle, and social status [7]. It can also provide an emotional pick-up, both mentally and physically. It can act as a relaxer or a mental clarifier. It increases blood circulation and has warming effects; it is psychologically comfortable and has pleasant associations, along with its appreciated aroma and taste [8].

Past research identified different drivers of coffee consumption, including mixed expectations about its caffeine content. Coffee has been widely studied in relation to its positive or negative health-related outcomes. Controversial information about coffee is released and given to consumers, thus creating uncertainty. Consumers have indeed reported to be confused regarding the health risks and benefits of coffee. Only $16 \%$ of U.S. consumers reported to be informed about the health aspects of coffee and $66 \%$ cope with reducing the amount of caffeine they consume [9]. The situation is similar in Europe, where $49 \%$ believe that coffee may cause health problems [10].

Despite coffee's great popularity, increased consumption across various countries, and increased interest in new coffee products, only a few studies have explored the motives and emotions of coffee consumption and not consumption. Past research mainly focused on consumers' coffee consumption behaviour $[4,7,11-13]$. There is limited understanding of consumers' emotional approach towards coffee, and what influences a positive and negative inclination towards coffee consumption. This paper aims to understand consumers' preference and reasons for coffee consumption, including emotions, attitudes, and perceptions that drive coffee consumption and non-consumption. The identification of the emotions and factors that guide consumers in drinking or not drinking coffee complements past research findings, and provides a more comprehensive understanding of coffee consumption behaviour.

Moreover, past research supports that countries may have different coffee consumption behaviours [10,14]. The present study aims at highlighting the existence of various emotional and motivational approaches in two different countries, that is, Italy and Portugal. Both countries have a wide coffee consumption culture. Thus, it is relevant to explore whether there are country-specific emotions and motives to coffee consumption and non-consumption. The study outcomes can support the definition of research-based marketing strategies. Thus, this research objective is to fill the current literature gaps by addressing three research questions: (i) What are the emotions and habits of coffee consumption? (ii) What are the motives of coffee consumption and non-consumption? and (iii) How relevant is the coffee health impact perception in consuming or not consuming coffee? The research will highlight differences and similarities between Italian and Portuguese consumers.

\section{Literature Review}

\subsection{The Experience and Emotions of Coffee Consumption}

Food consumption patterns have modified in the last decades and are expected to evolve following consumers' preferences and new lifestyles. The general interest is less inclined towards commodity food products purchased and consumed in a massive way [15]. In recent years, consumers' perspective has been subjected to a modernisation where aesthetic, uniqueness, and handicraft are expected products' values. Functionality has lost its relevance in a culture where people have the need to experience the whole context of emotions deriving from enjoyment of a specific product. Therefore, firms have changed their evaluation criteria when launching new products or presenting alternatives. The simple "measurement of liking/acceptability/preference" in consumer evaluation does not fully capture the complexity of elements that drive the food choice [16].

Emotions are considered essentials, driving people through the choice of different options. Brands are in charge of differentiating their products according to the different emotions they provide. Studies 
indicate that coffee has the capability to impact human wellbeing by influencing life in various subjective ways, such as body functioning, physical health, mood, emotions, and social relationships [17]. Coffee has the strength to modify people's feelings and mood. Moreover, coffee consumption can be driven by the lack of calories it contains [18]. Coffee is one of the products celebrated for its organoleptic characteristics, that create a unique sensorial experience [19]. Preparation of coffee involves mainly smell and taste, while the sight is entailed during the whole process [20].

\subsection{Coffee Consumers' Habits and Consumption Motives}

Food and beverages are consumed by people according to different motivations, in different places, and for different occasions. Consumers' purchasing behaviour habits are mainly driven by expected taste and flavour, as rarely is there a chance to use the senses to judge a product while being in supermarkets [21]. Expectations and previous knowledge replace the missing opportunity of experiencing taste and flavour before buying. The expectations are stimulated by the food packaging characteristics.

There are various drivers of coffee consumption. Taste and smell are the main reasons for drinking coffee. Other important motives of coffee consumption are socialisation, consumption setting, enjoying coffee at home, at work, and with different people, and the material aspects of the cup (fabric, type of spoon, etc.) [10]. A recent research review supports that coffee consumer behaviour is influenced by the following coffee attributes: sustainability labelling, organic, Fairtrade, country of origin, type of coffee (espresso, filter, instant, single cup, with milk, iced), intrinsic attributes (roast degree, specialty coffee), and extrinsic attributes (brands and packaging) [7]. In the meal experience, coffee has a double role. It is an opportunity to socialize, a daily ritual, a part of special occasions, and a nutritional intake, aiming to increase blood pressure or stimulate alertness.

\subsection{Consumers' Perception of the Relationship Between Coffee and Health}

The increasing rates of diet-related diseases such as obesity, heart disease, and diabetes across the world during the last decades have raised attention towards nutrition and healthy diets, pushing food companies to differentiate their products with healthier alternatives. Unhealthy diets together with sedentary lifestyles are considered the two major drivers of the higher disease rates.

One of the main aspects that acts as driver and barrier to coffee consumption concerns health beliefs [22]. The same effect produced by coffee can lead the consumer to want to consume it or not. Coffee is often consumed for the beneficial effects that the consumer perceives, such as anti-migraine or energising effects [23]. More often, however, coffee is considered harmful, and avoided by those suffering from insomnia or anxiety [24]. Recent studies carried out show that only $25 \%$ of the interviewed people link coffee with positive health effects (e.g., anti-migraine effect) [25]. Around 80\% of the respondents thought that drinking coffee increased blood pressure. The relationship between coffee consumption and the perception of coffee health impact has been limitedly studied and mainly in Europe [25]. Despite coffee being a drink included in low-calorie diets [11,22], consuming coffee is not yet considered a health-oriented behaviour [26]. Until now, consumers still know little about the beneficial effects that coffee can have on human health. It is mainly perceived as a stimulant.

\subsection{Coffee Non-Consumption Motives}

The food non-consumption behaviour is complex and can be driven by various factors [24,27]. Consumers may intentionally decide not to consume a specific product, be against one product and opt for an alternative, and be inadequate for a certain product due to some limitations, for example age limits. Other conceptual frameworks classify non-consumption to include a consumption behaviour that rejects, restricts, and reclaims a good. Rejection is about avoiding the consumption of some goods, restriction is about the reduction of some goods, reclaiming represents an ideological shift regarding the processes of acquisition, use, and dispossession. 
There are consumers that choose not to consume coffee. Consumer behaviour research studies mostly focus on the reasons for consuming coffee. There are limited studies on the reasons for not consuming coffee. Past research supports that the same elements may have a role both in driving or limiting coffee consumption [7]. Key coffee attributes that notably impact the consumers' non-consumption attitude are aroma, taste, and flavour [24,28]. The negative relationship between coffee and its flavour is due to the bitterness of some types of coffees $[4,24,28]$. It is interesting to note that taste is also the most appreciated attribute of coffee among those who consume it [24,28]. Moreover, not having the habit to consume coffee is another reason to explain coffee consumption reluctance $[24,28]$. Concerns about the health effects of coffee also play a negative role in coffee consumption. Consumers associate coffee with anxiety, insomnia, and gastric problems such as heartburn and ulcers. However, there may be a possible interest in a coffee with functional characteristics among non-coffee users [25,28].

\subsection{Methodological Scales for Consumer Emotion Measurement}

A food product is no longer evaluated only for its sensory characteristics but also for the emotions it arouses in the consumer. Over time, various methodological scales have been developed to identify and measure the emotions that food products arouse. The most recent methods are the result of an evolution of evaluation scales, which have undergone various advancements. A recent literature review analysed the methods used to assess the emotions evoked by the food experience [29]. The most relevant methods are analysed below.

First, in the 1970s, the Profile of Mood States (POMS) was developed to assess people's mood. It uses 65 mood terms anchored to a Likert five-point rating scale. It measures mood in six dimensions: tension-anxiety, depression-dejection, anger-hostility, vigour-activity, fatigue-inertia, and confusion-bewilderment [30]. Moreover, in 1965, the Multiple Affect Adjective Check List (MAACL) was defined and then revised in 1985 [31]. The last version was integrated with two positive scales, that is, arousal and activation, and three negative scales, that is, anxiety, depression, and hostility. These first questionnaires and related measurement scales were initially developed for clinical screening, and aimed at assessing the emotional state of patients. Then, they started to be applied to food and product development laboratories.

Second, the Food Choice Questionnaire [32] was developed to identify the determinants of food choices. Nine factors are identified, including customers' mood. Laros and Steenkamp (2005) [33] listed 173 negative and 143 positive emotions. In 2008, Desmet and Schifferstein [34] measured responses to positive and negative emotion-terms, which they called pleasant and unpleasant. More recently, King, Meiselman, and Carr (2010) [35] defined the EsSense Profile ${ }^{\mathrm{TM}}$, a list of 39 emotion-terms related to general food consumption. In order to assess the overall acceptability of the product, the EsSense Profile ${ }^{\mathrm{TM}}$ has been extended with nine hedonic-focused items. In 2016, a new version of the EsSense Profile ${ }^{\mathrm{TM}}$, the EsSense Profile25, was created with the aim of shortening the previous version, by reducing the number of words from 39 to 25 [36]. A five-point Likert scale (from $1=$ not at all, to $5=$ extremely) has been used to measure emotions' intensity. Standard questionnaires applied to food products were no longer sufficient to specifically identify the emotional profile of a specific product. To address the limitations of the available approaches, Spinelli et al. (2014) [37] developed a food product-specific questionnaire (EmoSemio). EmoSemio is a product-specific questionnaire, presented in discursive form, and adopting a specific language and culture perspective. In EmoSemio, the emotions are presented by using full sentences. It developed from one-to-one interviews based on a modified version of the Repertory Grid Method (RGM) [38]. In RGM, the differences between the products under consideration are described through the use of three elements that act as a stimulus to elicit the respondents' views. Other questionnaires use emotional vocabulary related to food products, such as the EmoSensory Profile (EMP) [39], the Empathic food test (EFT), the Consumer-Defined Check-All-That-Apply (CD-CATA) [40], and the Rate-All-That-Apply (RATA) [41]. EPT uses a list of 14-17 emotional and 13 sensory terms, and EFT uses 12 empathic terms. The CD-CATA and 
RATA techniques are, respectively, an evolution and a variant of the Check-All-That-Apply (CATA) in which the respondent is asked to choose and rate the most suitable terms to describe the tested food product [42].

Finally, specific studies were conducted with the aim of investigating the reasons for coffee consumption and to formulate a specific vocabulary to identify the full range of emotions that it arouses. In 1988, Graham [12] tested 18 motives for consuming coffee and tea to analyse this product's consumption drivers. Four principal motives were identified, two concerning the social sphere-sociability and beverage - and two regarding personal effects—stimulant and relief. Based on Graham's [12] study, Agoston et al. (2017) [13] developed a 39-item Motives for Caffeine Consumption Questionnaire (MCCQ). Habit, ceasing fatigue, invigoration, improving concentration, taste, smell, symptom management, mood, and social reason were the main identified categories. In 2014, Bhumiratana, Ashikari, and Chambers [43] identified a vocabulary describing the experience induced by coffee consumption. A total of 44 terms of emotion were identified through a focus group, 17 of which confirmed the EsSense Profile ${ }^{\circledR}$. The remaining 27 terms derived from the uniqueness of the experience generated by different factors, such as the time of day, the situation, cultures, traditions, and the context of consumption. Thanks to the identification of this comprehensive scale, the list of terms describing the coffee consumption experience (CDE) has been defined. Recently, Kanjanakorn and Lee (2017) [8] compared the EsSense Profile ${ }^{\circledR}$ and the specific scale developed for coffee consumers (CDE) to evaluate the behaviour of coffee consumers and the change in their emotions when drinking coffee. In addition to these specific studies on coffee, past studies focused on consumers' emotions by comparing different product categories [35,44], and analysing a specific product, such as chocolate [45] and blackcurrant squashes [40]. However, up to now the literature has focused on the emotions raised by the experience of drinking coffee or other food products in people who consume it. There is limited knowledge on the reasons that push a consumer not to consume a specific product. In particular, the present study contributes to the definition of a deeper understanding of the coffee consumers' and non-consumers' behaviour.

\section{Method}

\subsection{Data Collection}

The data collection process obtained data and information from Italian and Portuguese consumers. Respondents were coffee consumers and non-consumers. The interviews were carried out face-to-face, by telephone, and online. The survey was carried out in Portugal-Lisbon urban area, from January to February 2019, and in Italy_Bologna urban area, from February to March 2019. A questionnaire testing phase was carried out in December 2018 to fine-tune unclear questions and develop a robust data collection instrument. Interviews were carried out in public places, such as bars, restaurants, parks, and malls. Survey filling lasted around 8 minutes. A total of 467 consumers participated in the study. Respondents were not remunerated for their participation. After data cleaning, the convenience sample for data elaboration included 419 questionnaires. The data were gathered with the support of Qualtrics, a web-based software. It was used to upload responses during the face-to-face interviews and online responses. Online questionnaire completion was made possible by using an online link or a Quick Response (QR) code sent to respondents via email.

The sample included 49\% respondents in Portugal and 51\% in Italy (Table 1). There was a good gender balance. A total of $61 \%$ of the respondents were younger than the average age, which was 35.2 years old, with a minimum age of 18 years old and maximum age of 91 years old. The level of education was high, as most of the respondents had an academic degree. Most of the respondents lived in households with at least two members, and had no children. The net family income was low or medium. The vast majority of respondents were highly interested in a healthy diet. There were no significant differences among the two countries. 
Table 1. Sample characteristics.

\begin{tabular}{|c|c|c|c|}
\hline & Total & Portugal & Italy \\
\hline Gender & $\%$ & $\%$ & $\%$ \\
\hline Women & 58 & 61 & 55 \\
\hline Men & 42 & 39 & 45 \\
\hline Total & 100 & 100 & 100 \\
\hline \multicolumn{4}{|l|}{ Level of education } \\
\hline No academic degree & 30 & 16 & 43 \\
\hline With academic degree & 70 & 84 & 57 \\
\hline Total & 100 & 100 & 100 \\
\hline \multicolumn{4}{|l|}{ Age } \\
\hline From 18 to 29 years old & 52 & 59 & 45 \\
\hline From 30 to 39 years old & 15 & 18 & 11 \\
\hline From 40 to 49 years old & 11 & 11 & 11 \\
\hline From 50 to 59 years old & 15 & 9 & 21 \\
\hline From 60 to 69 years old & 5 & 1 & 9 \\
\hline From 70 years old & 2 & 1 & 4 \\
\hline Total & 100 & 100 & 100 \\
\hline \multicolumn{4}{|l|}{ Members in the household } \\
\hline Single person & 15 & 15 & 14 \\
\hline From 2 to 3 & 41 & 42 & 40 \\
\hline$>3$ & 45 & 43 & 46 \\
\hline Total & 100 & 100 & 100 \\
\hline \multicolumn{4}{|l|}{ Children in the household } \\
\hline None & 79 & 76 & 82 \\
\hline Between 1 and 2 children & 19 & 23 & 16 \\
\hline$>3$ children & 2 & 1 & 2 \\
\hline Total & 100 & 100 & 100 \\
\hline \multicolumn{4}{|l|}{ Net yearly family income } \\
\hline$<15,000$ Euro & 19 & 19 & 19 \\
\hline 15,001-28,000 Euro & 28 & 29 & 26 \\
\hline $28,001-55,000$ Euro & 33 & 32 & 35 \\
\hline $55,001-75,000$ Euro & 12 & 13 & 12 \\
\hline$>75,000$ Euro & 8 & 8 & 8 \\
\hline Total & 100 & 100 & 100 \\
\hline
\end{tabular}

Note: Total valid interviews: 419, with 205 in Portugal and 214 in Italy.

\subsection{Questionnaire Structure}

Data gathering was based on a questionnaire with close-ended questions. The questionnaire was available in three languages (i.e., English, Italian, and Portuguese) to allow consumers easy participation in the study. The questionnaire was divided into different sections (Figure 1).

The preliminary section presented the survey, provided information about the research institution promoting the study and the length of completion, asked confirmation of minimum age, set at 18 years old, provided information on the anonymity and confidentiality of the survey, asked to confirm the relevant informed consent before proceeding with the questionnaire. The first section asked if the respondent drank coffee, decaffeinated, or did not drink coffee. This was a filter question. The rest of the questionnaire had a number of questions differentiated between coffee consumption and not consumption consumers. If the consumer responded positively, the second section of the survey gathered information on coffee drinking habits, including consumption frequency (1 cup per day, 2-3 cups per day, more than 3 cups per day), type of coffee, occasions of consumption (at breakfast, after a meal-lunch/dinner, midmorning/afternoon breaks), place of consumption (at home, at bar/café/coffee house, workplace). If the consumer responded negatively, the survey skipped to the third section. 


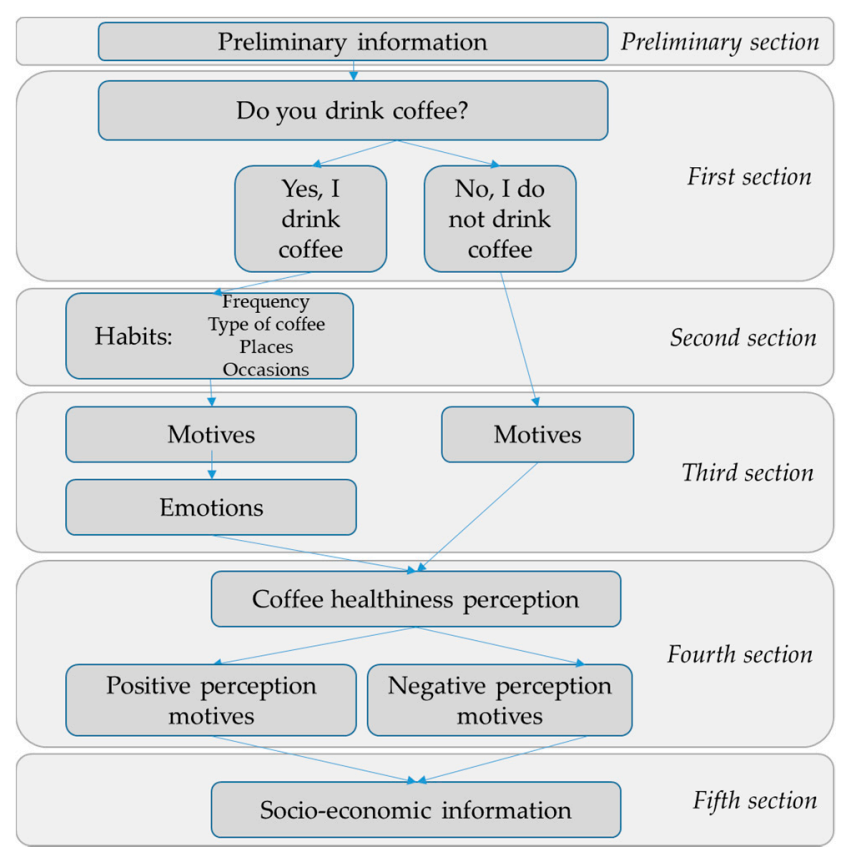

Figure 1. Questionnaire structure.

The third section included items to explore the motives of coffee consumption, including taste, health, alertness, personal habit, family food tradition, socialisation, mood, reduction of headaches, and management of blood pressure. Coffee consumers selected the level of importance of each of the proposed items on a five-point Likert scale (from $1=$ not at all important, to $5=$ extremely important). Then, coffee consumers selected the emotions evoked by coffee consumption. The list of proposed emotions was based on the Coffee Drinking Experience lexicon [43] and on the EsSense Profile [36]. In addition, the third section aimed at exploring the motives of coffee non-consumption, including taste, doctor recommendation, perception of unhealthiness, negative influence on anxiety, increases nervousness, stimulates insomnia, not a personal habit, and other. Consumers selected yes or no for each question item.

The fourth section explored respondents' coffee health or unhealthy perceptions of coffee consumers and non-consumers. They were asked to rate to what extent coffee is a healthy food based on a five-point Likert scale (1: unhealthy, 5: healthy). If consumers answered from 3 upwards, the questionnaire asked why they considered coffee as healthy. If consumers answered a value lower than 3, they were invited to explain why they considered coffee as unhealthy. Consumers positively inclined were provided with possible explicable answers, including coffee has a natural aspect, it is a plant-based beverage, for its caffeine content, and because a regular consumption of moderate quantities of coffee decreases the risk of stress and anxiety; depression and headache; and cardiovascular diseases, such as high cholesterol [46-49]. Consumers negatively inclined towards coffee's health impact were provided with possible answers, including the caffeine content, other nutrient components present in the beverage, the roasting processes of the beans, drinking coffee, even in moderated quantities, excessively increases blood pressure, negatively influences the absorption of minerals and calcium, and increases the risk of cancer. The provided answers were based on the literature regarding possible health impact of coffee (Appendix A). Respondents could opt for "I do not know", and "I do not have a specific opinion". At the end of this section, respondents were asked if they were interested in health-certified coffee, which was explained as a coffee with a health claim [25].

The last section of the questionnaire aimed at gathering socio-economic information, such as nationality, gender, level of education, age, members in the household, children in the household, and net yearly family income. 


\subsection{Data Analysis}

Data elaboration included different steps. First, it aimed at analysing coffee consumers' and non-consumers' characteristics and habits. To test the significance of each variable, the chi-square test or Student's $t$-test were calculated as appropriate.

Second, the research analysed consumers' emotions when drinking coffee in each country, calculating the average value of each emotion. Emotion ratings between Italian and Portuguese were tested with the Student $t$-test to confirm the differences' significance. Then, the research identified the existing latent factors in consumers' coffee consumption emotions to identify main emotions. The principal components method (PCA) and Varimax rotation were applied. A total of 23 of the initial 25 items on coffee emotions had factor loadings above 0.56 and were grouped into five components. The Kaiser-Meyer-Olkin measure of sampling adequacy and Bartlett's test of sphericity were calculated to assess the appropriateness of the data for factor analysis. The Kaiser-Meyer-Olkin index was 0.848. Bartlett's test of sphericity was highly significant $(0.000)$. The internal consistency of the measurement items of factors was satisfactory (Cronbach's $\alpha=0.796-0.926)$ and no severe violations of the normal distribution assumption were detected. The internal consistency and convergent and discriminant validity of each component were verified using composite reliability (CR). CR values were from 0.722 to 0.914 . Values were satisfactory and acceptable [50,51]. The average variance extracted (AVE) provides a measure of convergent validity, and ranged from 0.501 to 0.641 . These were satisfactory [52]. The square root of each construct's AVE was calculated to ensure it was greater than its bivariate correlation with other constructs in the model and thus confirm discriminant validity. The results confirmed the reliability and validity of the research components. These results indicate that the data were appropriate for use in the analysis. The choice of factors was made on the basis of the Eigen value criterion being higher than 1 . The cumulated variance explained by the factors was $69.15 \%$. The factors were saved as new variables and became the main emotions expressed by consumers.

Third, data elaboration aimed at exploring possible relationships between the rating of main emotions and the quantity, places, and occasions of coffee consumption. This analysis was carried out testing the chi-square or Student's $t$-test values, as appropriate.

Fourth, the research analysed the motives for drinking and not drinking coffee in relation to country, gender, and age. Finally, consumers' perception of coffee healthiness was analysed to explore in detail to what extent this perception was relevant in the different countries. Data elaboration was carried out with the support of SPSS (IBM statistics, version 25).

\section{Results}

Research results show the emotions and motives of coffee consumption and non-consumption, and to what extent coffee health perception influences coffee (non)consumption. Coffee consumers were the majority of respondents (274, equal to $65 \%$ of respondents). There was no significant country, gender, and academic degree level difference among coffee consumers and non-consumers (Table 2) (non-significant chi-square values). The age was fairly significant, as supported by the Student $t$-test (Levene's test $\mathrm{F}=3.544, p=0.06,95 \% \mathrm{CI}$ ) used to compare the age difference between coffee and non-coffee consumers. Young women tended not to drink coffee. The vast majority of coffee consumers drank coffee at home $(74.5 \%)$ and at breakfast $(74.1 \%)$, and half of them drank it outside the house and after a meal. Drinking coffee at the workplace was quite common (39.7\%). 
Table 2. Coffee consumers' and non-consumers' socio-economic characteristics and consumers' coffee drinking habits (\%).

\begin{tabular}{|c|c|c|c|c|}
\hline & Women & Men & Total & Chi-Square \\
\hline Yes, I drink coffee & 57.6 & 42.4 & 100 & 0.498 \\
\hline No, I do not drink coffee & 58.8 & 41.2 & 100 & \\
\hline \multirow[t]{2}{*}{ Total } & 57.8 & 42.2 & 100 & \\
\hline & Italy & Portugal & Total & Chi-Square \\
\hline Yes, I drink coffee & 54.8 & 45.2 & 100 & 0.384 \\
\hline No, I do not drink coffee & 49.2 & 50.8 & 100 & \\
\hline \multirow[t]{2}{*}{ Total } & 53.8 & 46.2 & 100 & \\
\hline & $\begin{array}{l}\text { Below or equal to } \\
\text { average age }\end{array}$ & $\begin{array}{c}\text { Above } \\
\text { average age }\end{array}$ & Total & $\begin{array}{c}\text { Student's } \\
t \text {-test }\end{array}$ \\
\hline Yes, I drink coffee & 58.4 & 41.6 & 100 & $0.06^{*}$ \\
\hline No, I do not drink coffee & 67.8 & 32.2 & 100 & \\
\hline \multirow[t]{2}{*}{ Total } & 60.1 & 39.9 & 100 & \\
\hline & $\begin{array}{c}\text { Without } \\
\text { academic degree }\end{array}$ & $\begin{array}{c}\text { With } \\
\text { academic degree }\end{array}$ & Total & Chi-Square \\
\hline Yes, I drink coffee & 28.3 & 71.7 & 100 & 0.146 \\
\hline No, I do not drink coffee & 36.1 & 63.9 & 100 & \\
\hline Total & 29.6 & 70.4 & 100 & \\
\hline \multicolumn{5}{|c|}{ Habits of coffee consumers ** } \\
\hline Where-at home & \multicolumn{2}{|c|}{ Where—at bar/café/coffee house } & $\begin{array}{l}\text { Where- } \\
\text { at workplace }\end{array}$ & \\
\hline 74.5 & \multicolumn{2}{|c|}{51.4} & 39.7 & \\
\hline When—at breakfast & \multicolumn{2}{|c|}{ When-after a meal (lunch/dinner) } & $\begin{array}{c}\text { When- } \\
\text {-midmorning/ } \\
\text { afternoon breaks }\end{array}$ & When-Other \\
\hline 74.1 & \multicolumn{2}{|c|}{54.8} & 54.1 & 5.2 \\
\hline
\end{tabular}

Note: * Significant at $p<0.10,{ }^{* *}$ Percentages were calculated for coffee consumers. Consumers could tick more than one proposed habit.

\subsection{Emotions Evoked by Coffee Consumers}

Consumers drinking coffee have a mix of emotions (Figure 2). They feel active, comfortable, motivated, productive, and satisfied. The country-focused analysis supported that Portuguese consumers have more intense emotions compared to Italian consumers when drinking coffee. There was a limited number of emotions significantly different among countries. Negative emotions, such as being worried, annoyed, bored, disgusted, grouchy, and off-balanced, were similar. Positive emotions differed more notably, in particular when consumers feel enjoyment, merry, productive, satisfied, and special. The research aimed at exploring whether emotions merge into a limited number of latent factors that may effectively express the array of various feelings (Table 3). Overall consumers' emotions can be summarised into five main feelings: (i) annoyance: consumers feel annoyed, bored, disgusted, grouchy, off-balanced, and worried. These feelings were perceived similarly in Italy and in Portugal. Yet, consumers tend not to have negative feelings when drinking coffee (average value: 1.60); (ii) enjoyment: consumers feel free, enjoyed, pleased, special and warm. The level of enjoyment is limited (average value: 2.77); (iii) self-fulfilment: emotions of fulfilment, relaxation, soothing were perceived similarly in Portugal and Italy, and this factor has limited significance for consumers (average 2.96). The last two factors are the most notable for consumers. When drinking coffee, consumers tend to feel comfortable (average 3.10) and active (3.54). Feeling comfortable (main feeling iv) means being balanced, comfortable, and satisfied, and being active (main feeling $\mathrm{v}$ ) is a mix of emotions including feeling active, motivated, and productive. 


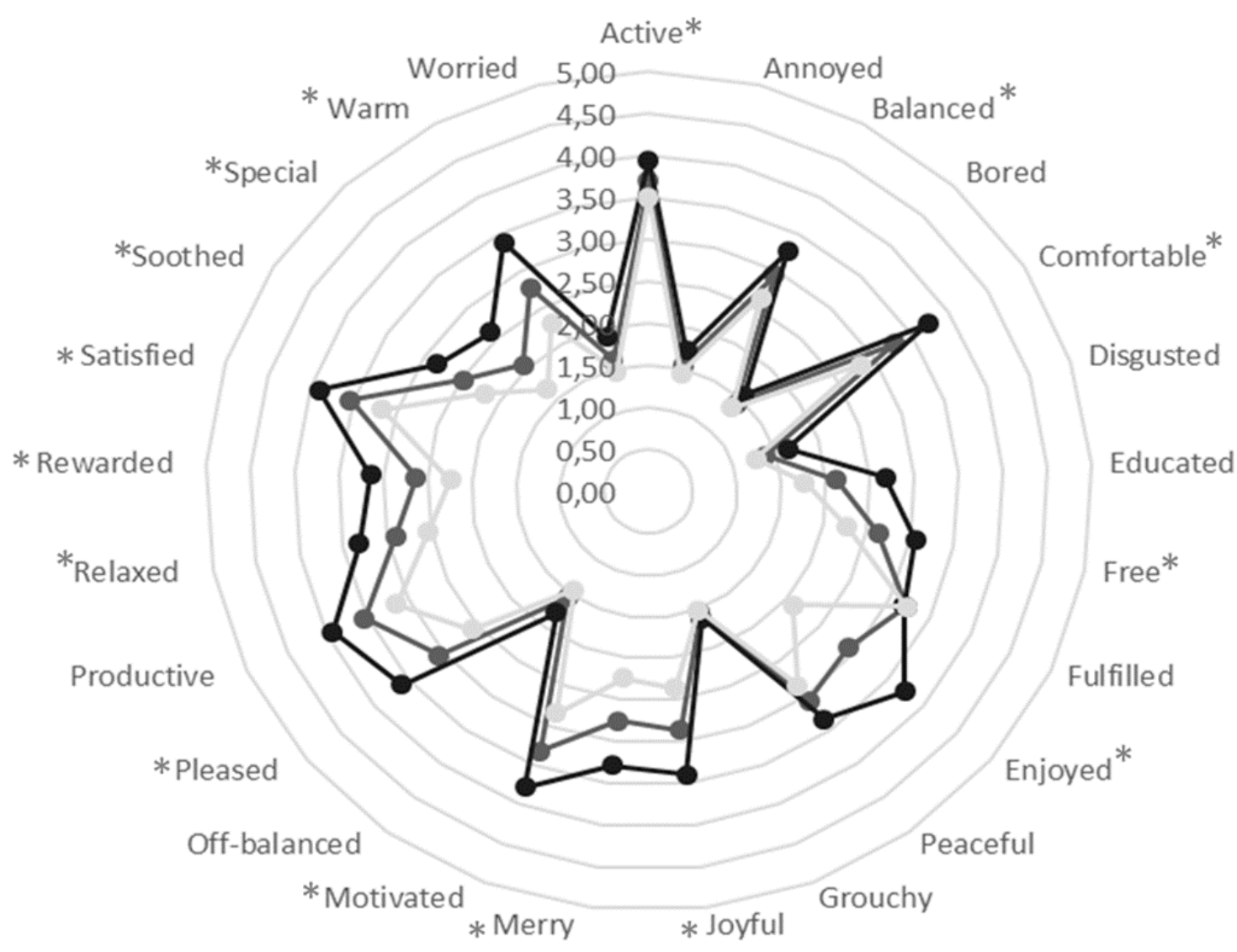

Figure 2. Emotion ratings of coffee consumers in Italy and Portugal. Note: Black: Portuguese consumers; Grey line: Total consumers; Light grey line: Italian consumers. * $p$-value of $t$-test testing with $p$-value equal or below 0.001 , aimed to compare Italian and Portuguese emotion ratings.

Table 3. Factor analysis of emotions of coffee consumers.

\begin{tabular}{|c|c|c|c|c|c|}
\hline & Annoyance & Enjoyment & Self-fulfilment & Comfortable & Active \\
\hline Annoyed & 0.865 & & & & \\
\hline Bored & 0.820 & & & & \\
\hline Disgusted & 0.804 & & & & \\
\hline Off-balanced & 0.785 & & & & \\
\hline Worried & 0.764 & & & & \\
\hline Grouchy & 0.763 & & & & \\
\hline Cronbach's $\alpha$ & 0.914 & & & & \\
\hline Free & & 0.877 & & & \\
\hline Enjoyed & & 0.763 & & & \\
\hline Warm & & 0.745 & & & \\
\hline Special & & 0.732 & & & \\
\hline Pleased & & 0.648 & & & \\
\hline Joyful & & 0.603 & & & \\
\hline Merry & & 0.592 & & & \\
\hline Cronbach's $\alpha$ & & 0.926 & & & \\
\hline Fulfilled & & & 0.746 & & \\
\hline Relaxed & & & 0.738 & & \\
\hline Soothed & & & 0.655 & & \\
\hline Cronbach's $\alpha$ & & & 0.805 & & \\
\hline
\end{tabular}


Table 3. Cont.

\begin{tabular}{|c|c|c|c|c|c|}
\hline & Annoyance & Enjoyment & Self-fulfilment & Comfortable & Active \\
\hline Comfortable & & & & 0.798 & \\
\hline Peaceful & & & & 0.698 & \\
\hline Balanced & & & & 0.690 & \\
\hline Satisfied & & & & 0.617 & \\
\hline Cronbach's $\alpha$ & & & & 0.796 & \\
\hline Active & & & & & 0.833 \\
\hline Productive & & & & & 0.781 \\
\hline Motivated & & & & & 0.567 \\
\hline Cronbach's $\alpha$ & & & & & 0.809 \\
\hline Variance explained (\%) & 18.95 & 18.32 & 14.04 & 10.24 & 7.60 \\
\hline Average & 1.60 & 2.77 & 2.96 & 3.10 & 3.54 \\
\hline Std. Deviation & 0.83 & 1.22 & 1.17 & 1.02 & 1.04 \\
\hline \multicolumn{6}{|c|}{ Convergent validity and discriminant validity } \\
\hline & Annoyance & Enjoyment & Self-fulfillment & Comfortable & Active \\
\hline Annoyance & 0.641 & & & & \\
\hline Enjoyment & 0.829 & 0.510 & & & \\
\hline Self-fulfilment & 0.064 & -0.320 & 0.510 & & \\
\hline Comfortable & 0.257 & -0.653 & 0.040 & 0.501 & \\
\hline Active & 0.057 & -0.295 & 0.796 & 0.233 & 0.541 \\
\hline CR & 0.914 & 0.877 & 0.756 & 0.722 & 0.775 \\
\hline
\end{tabular}

"Extraction Method: Principal Component Analysis. Rotation Method: Varimax with Kaiser Normalisation." Note: Diagonal data (in italics) represent Fornell and Larcker's average variance extracted (AVE). Sub-diagonal figures represent the inter-construct correlations. Total variance explained: $69.15 \%$.

\subsection{Coffee Consumers' Emotions and Habits of Coffee Consumption}

The research study explored the relationships between the identified main emotions and habits of coffee consumption (Table 4). There was no difference between the level of active, comfortable, self-fulfilment, and enjoyment emotions between low or high level of coffee consumption (non-significant chi-square values). This means that all coffee consumers feel active, comfortable, self-fulfillment, and enjoyment when drinking coffee with no difference depending on the quantity of coffee usually consumed. Coffee consumers that drink a higher quantity of cups of coffee feel more comfortable (chi-square value: 0.098 ) when drinking coffee, compared to those that drink fewer cups of coffee. Results support that the sense of comfortableness is more intense among high-frequency coffee consumers.

The research explored the relationships between the level of emotions and the different places and occasions of coffee consumption (Table 5). Consumers that feel mostly comfortable and active tend to equally drink coffee at home, outside, and at the workplace. The vast majority of the people that feel annoyed feel these emotions wherever they are, at home, outside, and at the workplace. Results support that the place of consumption does not influence the feelings, as the same feeling will be perceived in all places. Consumers feel comfortable and active anywhere they drink. 
Table 4. Relationships between emotion rating and quantity of coffee consumed (\%).

\begin{tabular}{|c|c|c|c|c|}
\hline & Below Moderate & Moderate or Above & Total & Chi-Square \\
\hline \multicolumn{5}{|c|}{ Annoyance } \\
\hline Equal to or below 3 cups coffee/day & 60.4 & 39.6 & 100 & 0.434 \\
\hline Above 3 cups coffee/day & 58.0 & 42.0 & 100 & \\
\hline Total & 60.0 & 40.0 & 100 & \\
\hline \multicolumn{5}{|c|}{ Enjoyment } \\
\hline Equal to or below 3 cups coffee/day & 52.9 & 47.1 & 100 & 0.514 \\
\hline Above 3 cups coffee/day & 52.0 & 48.0 & 100 & \\
\hline Total & 52.8 & 47.2 & 100 & \\
\hline \multicolumn{5}{|c|}{ Self-Fulfilment } \\
\hline Equal to or below 3 cups coffee/day & 47.9 & 52.1 & 100 & 0.194 \\
\hline Above 3 cups coffee/day & 40.0 & 60.0 & 100 & \\
\hline Total & 46.6 & 53.4 & 100 & \\
\hline \multicolumn{5}{|c|}{ Comfortable } \\
\hline Equal to or below 3 cups coffee/day & 51.3 & 48.8 & 100 & 0.098 * \\
\hline Above 3 cups coffee/day & 40.0 & 60.0 & 100 & \\
\hline Total & 49.3 & 50.7 & 100 & \\
\hline \multicolumn{5}{|c|}{ Active } \\
\hline Equal to or below 3 cups coffee/day & 23.6 & 76.4 & 100 & 0.197 \\
\hline Above 3 cups coffee/day & 16.7 & 83.3 & 100 & \\
\hline Total & 22.4 & 77.6 & 100 & \\
\hline
\end{tabular}

Note: * Significant at $p<0.01$; Emotion rating: Below moderate when below 3; Moderate or above when equal and above 3. The scale adopted was "1: not at all", "2: slightly", "3: moderately", "4: very", and "5: extremely" [36].

Table 5. Relationship between emotion rating and place and occasion of coffee consumption (\%).

\begin{tabular}{|c|c|c|c|c|c|c|c|c|c|}
\hline & \multicolumn{3}{|c|}{ Where: at Home } & \multicolumn{3}{|c|}{$\begin{array}{c}\text { Where: } \\
\text { at Bar/Café/Coffee House }\end{array}$} & \multicolumn{3}{|c|}{ Where: Workplace } \\
\hline & $\begin{array}{l}\text { Low } \\
\text { Level }\end{array}$ & $\begin{array}{l}\text { Medium/High } \\
\text { Level }\end{array}$ & Total & $\begin{array}{l}\text { Low } \\
\text { Level }\end{array}$ & $\begin{array}{l}\text { Medium/High } \\
\text { Level }\end{array}$ & Total & $\begin{array}{l}\text { Low } \\
\text { Level }\end{array}$ & $\begin{array}{l}\text { Medium/High } \\
\text { Level }\end{array}$ & Total \\
\hline Annoyance & 67.4 & 32.6 & 100 & 66.4 & 33.6 & 100 & 60.9 & 39.1 & 100 \\
\hline Enjoyment & 50.9 & 49.1 & 100 & 53.7 & 46.3 & 100 & 52.2 & 47.8 & 100 \\
\hline Comfortable & 47.7 & 52.3 & 100 & 40.3 & 59.7 & 100 & 46.1 & 53.9 & 100 \\
\hline Active & 32.9 & 67.1 & 100 & 32.9 & 67.1 & 100 & 34.8 & 65.2 & 100 \\
\hline \multirow[t]{3}{*}{ Self-fulfilment } & 43.5 & 56.5 & 100 & 47.7 & 52.3 & 100 & 52.2 & 47.8 & 100 \\
\hline & \multicolumn{3}{|c|}{ When: at breakfast } & \multicolumn{3}{|c|}{$\begin{array}{l}\text { When: after a meal } \\
\text { (lunch/dinner) }\end{array}$} & \multicolumn{3}{|c|}{$\begin{array}{c}\text { When: midmorning/afternoon } \\
\text { breaks }\end{array}$} \\
\hline & $\begin{array}{l}\text { Low } \\
\text { level }\end{array}$ & $\begin{array}{l}\text { Medium/High } \\
\text { level }\end{array}$ & Total & $\begin{array}{l}\text { Low } \\
\text { level }\end{array}$ & $\begin{array}{l}\text { Medium/High } \\
\text { level }\end{array}$ & Total & $\begin{array}{l}\text { Low } \\
\text { level }\end{array}$ & $\begin{array}{l}\text { Medium/High } \\
\text { level }\end{array}$ & Total \\
\hline Annoyance & 62.8 & 37.2 & 100 & 61.6 & 38.4 & 100 & 61.1 & 38.9 & 100 \\
\hline Enjoyment & 52.6 & 47.4 & 100 & 50.3 & 49.7 & 100 & 53.5 & 46.5 & 100 \\
\hline Comfortable & 46.5 & 53.5 & 100 & 50.3 & 49.7 & 100 & 46.5 & 53.5 & 100 \\
\hline Active & 35.8 & 64.2 & 100 & 38.4 & 61.6 & 100 & 33.8 & 66.2 & 100 \\
\hline Self-fulfilment & 45.1 & 54.9 & 100 & 47.8 & 52.2 & 100 & 50.3 & 49.7 & 100 \\
\hline
\end{tabular}

Furthermore, the research explored how the main feelings differ in the various occasions of coffee consumption; that is, at breakfast, after a meal, and during breaks (Table 6). Consumers feeling mostly comfortable and active feel similarly in all contexts. Consumers feeling annoyed also perceive this emotional status during all occasions of consumption. Results support that the level of main feelings consumers have when drinking coffee does not differ significantly in the different places and occasions of coffee consumption. 
Table 6. Motives for drinking coffee in relation to country, gender, age.

\begin{tabular}{|c|c|c|c|c|c|c|c|c|c|c|c|c|c|c|}
\hline & \multicolumn{2}{|c|}{ Total } & \multicolumn{2}{|c|}{ Italy } & \multicolumn{2}{|c|}{ Portugal } & \multicolumn{2}{|c|}{ Women } & \multicolumn{2}{|c|}{ Men } & \multicolumn{2}{|c|}{$\begin{array}{l}\text { Below the } \\
\text { Average Age }\end{array}$} & \multicolumn{2}{|c|}{$\begin{array}{l}\text { Above the } \\
\text { Average Age }\end{array}$} \\
\hline & Mean & SD & Mean & SD & Mean & SD & Mean & SD & Mean & SD & Mean & SD & Mean & SD \\
\hline I like the taste & 4.0 & 1.9 & 4.0 & 1.9 & 3.9 & 1.6 & 4.1 & 1.0 & 3.9 & 1.0 & 3.9 & 1.1 & 4.1 & 1.0 \\
\hline Good for health & 2.0 & 1.3 & 1.8 & 1.8 & 2.1 & 1.2 & 2.4 & 1.1 & 2.2 & 1.1 & 2.2 & 1.0 & 2.5 & 1.2 \\
\hline Makes me alert & 3.7 & 0.4 & 3.7 & 0.4 & 3.6 & 0.5 & 3.8 & 1.1 & 3.5 & 1.3 & 3.8 & 1.2 & 3.5 & 1.2 \\
\hline Part of a personal habit & 3.7 & 0.3 & 3.7 & 0.3 & 3.6 & 0.4 & 3.9 & 1.1 & 3.5 & 1.3 & 3.5 & 1.2 & 4.0 & 1.1 \\
\hline Family food tradition & 2.6 & 0.5 & 2.6 & 0.4 & 2.6 & 0.5 & 2.8 & 1.4 & 2.5 & 1.4 & 2.5 & 1.3 & 2.9 & 1.5 \\
\hline A way to socialize & 3.1 & 0.4 & 3.0 & 0.3 & 3.2 & 0.4 & 3.3 & 1.3 & 2.8 & 1.3 & 2.9 & 1.2 & 3.3 & 1.5 \\
\hline Improves my mood & 3.1 & 1.0 & 3.0 & 0.9 & 3.2 & 1.1 & 3.4 & 1.3 & 2.7 & 1.3 & 2.9 & 1.2 & 3.4 & 1.5 \\
\hline Helps me reduce headaches or manage blood pressure & 2.5 & 1.2 & 2.7 & 0.8 & 2.5 & 1.2 & 2.9 & 1.4 & 2.0 & 1.3 & 2.4 & 1.4 & 2.7 & 1.5 \\
\hline
\end{tabular}

Note: Question open to consumers drinking coffee. The question asked was: Which are the motives that make you drink coffee? Consumers selected the level of importance of each of the proposed items on a 5 -point Likert scale (from $1=$ not at all important, to $5=$ extremely important). 


\subsection{Consumers' Motives for Drinking and Not Drinking Coffee}

The research explored what the main motives are for drinking (Table 6) and not drinking coffee (Table 7). Findings support that the main motives for drinking coffee are the taste, sense of alertness, and habit. The least important motive is the belief that coffee is good for health. Motives are similar in Italy and Portugal. In Portugal, consumers associate coffee with socialisation and mood improvement. Moreover, there are some significant difference in terms of gender and age. Women and older people drink coffee as a personal habit, to socialise, to improve the mood. In addition, women appreciate coffee for reducing headaches, and older people drink it because it is a family food tradition. Results support that taste, sense of alertness, and habit are the key aspects of coffee drinking across country, gender, and age levels. Women and older people approach coffee drinking similarly, and there were no significant differences between the two countries analysed. Results support that the most common motives for not drinking coffee are the taste, habit unfamiliarity, and because coffee increases nervousness. Beliefs that it can be bad for health, anxiety, and insomnia stimulation are not perceived as valid motives for not drinking coffee. The motive of taste dislike was more relevant in Italy, among women, and, in particular, among younger respondents. Coffee unfamiliarity was more relevant in Italy, men, and, in particular, among younger respondents.

Table 7. Motives for not drinking coffee in relation to country, gender, age (\%).

\begin{tabular}{|c|c|c|c|c|c|c|c|c|c|c|}
\hline & $\begin{array}{c}\% \text { On } \\
\text { Coffee } \\
\text { Non- } \\
\text { Consumers }\end{array}$ & Italy & Portugal & Total & Women & Men & Total & $\begin{array}{l}\text { Below } \\
\text { the } \\
\text { Average } \\
\text { Age }\end{array}$ & $\begin{array}{c}\text { Above } \\
\text { the } \\
\text { Average } \\
\text { Age }\end{array}$ & Total \\
\hline Do not like the taste & 52.5 & 56.3 & 43.8 & 100 & 58.6 & 41.4 & 100 & 75.0 & 25.0 & 100 \\
\hline The doctor told me not to drink & 9.8 & 33.3 & 66.7 & 100 & 50.0 & 50.0 & 100 & 50.0 & 50.0 & 100 \\
\hline Bad for health & 6.6 & 75.0 & 25.0 & 100 & 0 & 100 & 100 & 25.0 & 75.0 & 100 \\
\hline Bad for anxiety & 4.9 & 66.7 & 33.3 & 100 & 33.3 & 66.7 & 100 & 66.7 & 33.3 & 100 \\
\hline Increases nervousness & 14.8 & 44.4 & 55.6 & 100 & 57.1 & 42.9 & 100 & 33.3 & 66.7 & 100 \\
\hline Stimulates insomnia & 8.2 & 60.0 & 40.0 & 100 & 40.0 & 60.0 & 100 & 60.0 & 40.0 & 100 \\
\hline Not a personal habit & 29.5 & 55.6 & 44.4 & 100 & 43.8 & 56.3 & 100 & 93.8 & 6.3 & 100 \\
\hline
\end{tabular}

Note: Question open to consumers not drinking coffee. The question asked was: Which are the motives that make you not drink coffee? Consumers selected yes/no to each question item. Other reasons: Intolerance, Allergy, Dizziness, Breastfeeding, Tachycardia, Nausea, Stomach problems.

\subsection{Focus on Health as an Element that Favours or Hinders Coffee Consumption}

Consumers' perception of coffee healthiness is a complex issue. The present research results support that consumers believe coffee is not good for health, but that is not the main reason for not drinking it. This result was confirmed across socio-economic characteristics of consumers. Thus, this study explored to what extent the reasons for coffee (un)healthiness differ across countries (Table 8). Results support that countries of belonging is a significant variable (Student t-test: Levene's test, $\mathrm{F}=3.068, p=0.07,95 \% \mathrm{CI})$, and most Portuguese consumers believe coffee is good for health $(52.9 \%)$, whereas most Italian consumers (68.4\%) believe is not good for health. Negatively inclined consumers believe that coffee is not good for health because it increases blood pressure and risk of cancer, and it contains caffeine and other components. Positively inclined consumers believe that coffee is good for health because it decreases the risk of stress, anxiety, depression, headache, and cardiovascular diseases, because it comes from a plant, and because it contains caffeine. The vast majority of consumers may be interested in a health-claimed coffee $(72.6 \%$ with non-significant chi-square values among the two countries). The same reasons may lead the consumers to believe in coffee healthiness and unhealthiness. This supports that consumers are confused or have misconceptions. 
Table 8. Consumers' perception of coffee healthiness (\%).

\begin{tabular}{|c|c|c|c|c|}
\hline Do You Think Coffee is Good for Health? (i) & Total & Italy & Portugal & $\begin{array}{c}\text { Student } \\
\text { t-Test }\end{array}$ \\
\hline Yes, coffee is good for health & 42.4 & 31.6 & 52.9 & $0.07 *$ \\
\hline No, coffee is not good for health & 57.6 & 68.4 & 47.1 & \\
\hline Total & 100 & 100 & 100 & \\
\hline Reasons why coffee is not good for health (ii): & Total (a) & Italy (b) & Portugal (b) & Total \\
\hline $\begin{array}{c}\text { Drinking coffee, even in moderated quantities, } \\
\text { increases blood pressure }\end{array}$ & 18.2 & 69.7 & 30.3 & 100 \\
\hline $\begin{array}{l}\text { Drinking coffee, even in moderated quantities, } \\
\text { increases the risk of cancer }\end{array}$ & 1.7 & 66.7 & 33.3 & 100 \\
\hline Because of its caffeine content & 27.8 & 67.3 & 32.7 & 100 \\
\hline Because of other coffee components & 3.6 & 61.5 & 38.5 & 100 \\
\hline $\begin{array}{c}\text { Because of the processes to which the beans are } \\
\text { subjected (e.g., roasting) }\end{array}$ & 4.4 & 56.3 & 43.8 & 100 \\
\hline $\begin{array}{c}\text { Because drinking coffee, even in moderated quantities, } \\
\text { negatively influences the absorption of calcium and } \\
\text { minerals }\end{array}$ & 1.9 & 42.9 & 57.1 & 100 \\
\hline I do not know & 10.2 & 55.6 & 44.4 & 100 \\
\hline Reasons why coffee is good for health (iii): & Total & Italy & Portugal & Total \\
\hline Because it is a natural product & 19.8 & 45.8 & 54.2 & 100 \\
\hline Because it comes from a plant & 9.4 & 55.9 & 44.1 & 100 \\
\hline Because it contains caffeine & 11.6 & 40.5 & 59.5 & 100 \\
\hline $\begin{array}{l}\text { Because regular consumption of moderate quantities } \\
\text { of coffee decreases the risk of stress and anxiety }\end{array}$ & 15.4 & 39.3 & 60.7 & 100 \\
\hline $\begin{array}{l}\text { Because regular consumption of moderate quantities } \\
\text { of coffee decreases the risk of depression and headache }\end{array}$ & 16.8 & 44.3 & 55.7 & 100 \\
\hline $\begin{array}{l}\text { Because regular consumption of moderate quantities } \\
\text { of coffee decreases the risk of cardiovascular diseases }\end{array}$ & 17.1 & 45.2 & 54.8 & 100 \\
\hline I do not know & 6.9 & 48.0 & 52.0 & 100 \\
\hline Would you be interested in a health-claimed coffee (iv)? & Total & Italy & Portugal & Chi-square \\
\hline Yes & 72.6 & 71.0 & 75.5 & 0.428 \\
\hline No & 27.4 & 29.0 & 24.5 & \\
\hline Total & 100 & 100 & 100 & \\
\hline
\end{tabular}

Note: (i) Scale from 1: unhealthy, to 5: healthy, the answers were grouped in 1 to $<3=$ unhealthy, and $\geq 3=$ healthy; (ii) Question open only to respondents that answered "No" to the above question (i); (iii) Question open only to respondents that answered "Yes" to the above question (i); (iv) Question open to all consumers; (a) the a column is the percentage of how many times the item was selected by all the respondents; $(b)$ the columns b represent whether the respondents that selected a given item are Italian or Portuguese. ${ }^{*}$ Significant at $p<0.10$.

\section{Discussion}

The research paper provides an innovative and complementary approach to the understanding of consumer behaviour of coffee drinking. The main aspects addressed by the current study are the emotions and motives for drinking and not drinking coffee, and to what extent consumers in various countries approach coffee drinking differently. Past studies analysed the coffee consumer behaviour habits, with limited attention to the emotions and motives for not consuming coffee [24]. Analysing non-coffee consumers' behaviour makes it possible to gather information and better understand what the barriers are to coffee consumption, and to what extent the motives, beliefs, and the health perception impact consumers' inclination towards coffee. Moreover, past studies mostly focused on single countries $[24,25,53]$. Past research pointed out that the acknowledged different cultural experience of coffee drinking may lead to differentiated approaches to coffee consumption. The current study sheds some lights on this aspect. 


\subsection{Emotions Evoked by Coffee Consumers}

The current research results support that coffee drinking impacts some emotions. In particular, it makes consumers feel comfortable and active. There are limited effects on enjoyment and self-fulfilment, and coffee drinking does not annoy. Coffee drinking brings a sense of wellbeing and dynamism experienced in different contexts and occasions of consumption. This confirms past research studies' findings $[7,17,35,44]$. Moreover, coffee drinking may stimulate different emotions in the different countries. Portuguese consumers significantly value coffee's capability of improving personal mood and socialisation. They have stronger emotions evoked by the coffee drinking experience, compared to Italian consumers. Portuguese respondents pointed out emotions of satisfaction, productivity, motivation, comfort, activity. These lead to higher pleasure and improvement of humour. Consistently with great interest towards the alertness given by coffee, Italian respondents mostly feel active, fulfilled, satisfied, and productive, indicating a general association of coffee with energy and contempt.

\subsection{Motives for Drinking and Not Drinking Coffee}

The results support the key role of taste in coffee consumption and non-consumption, as from previous studies $[20,24,28]$, in both countries. Taste is a double-edged sword, as it is the main factor pushing and limiting consumers towards drinking coffee. This finding is consistent with a previous study that highlighted the peculiarity of coffee consumption behaviour compared to a number of other caffeinated beverages [13], and another study that identified the pleasure of drinking coffee for its taste and smell, as the most important factors [25]. The current study supports that especially young women do not appreciate the coffee taste. The other key factors for drinking and not drinking coffee are habit and sense of alertness, as supported by both countries' respondents. Past studies showed that consumers drink coffee because it is a ritual or a daily routine [13], a tradition since childhood, and a part of breakfast or a snack [24]. Coffee consumers perceive distinctive feelings and emotions with all their senses [54]. Coffee is not an ordinary beverage [55], especially in Western countries [56]. The present study supports that habit is a key driver for coffee drinking in Italy and in Portugal. Moreover, current research supports past studies' findings $[55,57,58]$ on the relevance of alertness, energy, and awakening effects among the key motives of coffee consumption. Both countries' consumers confirmed this coffee drinking motivation. In addition, habit unfamiliarity and the belief that coffee increases blood pressure and nervousness are detrimental to coffee drinking [19,43]. The current study expands past knowledge supporting that taste, sense of alertness, and habit are key factors across genders and age levels.

The current study confirmed that breakfast is the most important time of consumption in both countries [55]. Coffee has an awakening power to face the day, and consumers usually drink two to three cups per day. Favourite consumption places are home, coffee houses, and at work, with some differences between the two considered countries. The Italian population mostly consumes coffee at home. Out-of-home consumption is relevant among Portuguese consumers. The study results confirm the relationship between coffee consumption frequency and emotions. High-frequency coffee consumers intensely enjoy and are self-fulfilled by coffee drinking. These results are consistent with studies supporting that drinking coffee improves mood and positive feelings [59].

\subsection{Coffee Health Impact and Coffee Consumption Perception}

The present study supports that consumers' perception of the coffee health impact is a valuable factor influencing consumer behaviour, with contradictory results. Positive health impact, such as alertness and energy provided by coffee, are elements that favourably incline consumers towards consumption. Negative heath impacts are key factors for not drinking coffee. One third of consumers support that coffee is bad for health, bad for anxiety, increase nervousness, stimulates insomnia, and doctors suggest not to drink it. This confirms past studies sustaining that factors such as being bad for health and medical restrictions have a prominent role in explaining coffee non-consumption [24,28]. The current research expanded past knowledge confirming the existence of differences based on gender 
and countries. Negative perception of coffee health impact is a significant factor for not consuming coffee among older men, and Italian consumers [25].

The current research results complement past studies on coffee health impact. European consumers are confused about the potential health effects of coffee, partly due to contradictory and not easily accessible information (Institute for Scientific Information on Coffee ISIC). Past studies revealed that only a fourth of the total examined population positively associated coffee with health, implying that the beverage continues to be appreciated for reasons not attributable to its healthy properties [25]. The present study provides further information and supports that there are differences between countries. Coffee drinkers and women were the two categories most interested in coffee's health benefits, while there were no differences based on age. Consumers' beliefs about coffee healthiness and unhealthiness overlapped. This supports consumers' limited knowledge and understanding on this issue. Negatively inclined consumers believed that coffee increases blood pressure and the caffeine content is bad for health. Positively inclined consumers believed coffee is healthy because it is a plant, a natural product, and it can decrease the risk of a number of health diseases. It is to be underlined that many consumers reported not having a specific opinion, confirming the confusion on this topic. Finally, the interest towards a health-claimed coffee confirmed past findings [25], and was found to be positive for coffee and non-coffee drinkers. Women were particularly favourable, consistent with their belief in coffee healthiness.

\section{Conclusions}

In the last 20 years, the global coffee market has undergone several changes, bringing coffee to be today the second most traded commodity in the world after crude oil. Coffee production has increased considerably as a response to higher demand, which has extended beyond traditional markets to include new importing countries and exporting countries. Coffee consumption has experienced an evolution, going from an industrial commodity to a specialty product, acknowledged as a unique product differentiated for its origin and artisanal production methods. Drinking coffee has become an exclusive experience. Coffee consumption behaviour cannot be understood only based on functional motives. Emotions influence eating behaviour, and emotions are key elements in coffee consumption. These perceptions influence consumers' food behaviour and consequently their mood and emotions. Also, coffee non-consumption behaviour is based on motives, and possibly also on misconceptions. These may be addressed with a better understanding of coffee consumers' emotions.

This research study provides both research-related and practical contributions. From a research perspective, it provides evidence on coffee consumption emotions and habits, and on what motives drive coffee consumption and non-consumption in different countries. The current exploration contributes to the expansion of knowledge on the non-consumption food behaviour research field. From a practical perspective, the increased knowledge provides a contribution to the coffee industry. Coffee industry managers gain a better understanding of consumers' functional and emotional needs, and this may lead to a comprehensive product conceptualisation. Coffee is a beverage product strongly embedded into personal and family traditions. The emotional attachment, perceptions, and beliefs of the properties of this product need to be understood to develop a long-term strategy to approach the coffee consumer and non-consumer. In an increasingly globalised market, strategies need to be based on the understanding of different countries' coffee consumers' and non-consumers' approaches. Understanding the functional needs, emotions, and perceptions of coffee consumers and non-consumers can reorient the coffee industry to successfully promote innovative coffee products, and possibly convey a coffee image that fits in with healthy eating behaviour.

\subsection{Managerial Implications}

The research results provide a set of information valuable to define coffee managerial strategies and product conceptualisation. First, some consumers search feelings and sensations rather than food products' functional value. The food product should provide unique and involving experiences. 
Consumers may take for granted functional features and benefits. They want to connect to food products, thanks to a product conceptualisation that fits into in their lifestyles. The products should touch their senses and their hearts, which stimulate their minds and provide an experience. Emotions are the key motivations why consumers sense, select, seek, and share their food product experiences. Coffee is an emblematic product that applies this approach. Coffee industry managers may design new coffee products taking into account the coffee emotions consumers have expressed. These are behaviour drivers that push consumers to consume it. Product marketers focus on satisfying consumers' functional wants rather their emotional needs. Companies' successful innovation is based on understanding and satisfying consumers' emotional needs through food. Whether and how we drink coffee are directly related to the emotional state of mind consumers experience during coffee consumption. Product designers have long been aware of the importance of intertwining emotional experiences with new products. The coffee industry should make consumers feel active, comfortable, and self-fulfilled. Coffee may be marketed as a drink to increase physical and mental performance, and to feel a sense of wellbeing. It may be positioned as a sport or energy drink, and as a wellness drink.

Second, the coffee industry needs to value coffee consumption drivers and to understand coffee consumption barriers, in order to conceptualise new coffee product development and effectively attract new consumers. The current research results support managerial decisions based on the different drivers and barriers for coffee consumption, and highlight the differences among countries. Coffee perception differs between cultures and countries, and its health properties are not well understood. Hence, the present study supports coffee stakeholders in meeting the expectations of coffee consumption and non-consumption, since they will be the factors actively influencing consumers' purchasing behaviour and affecting the coffee market. Consumers' bipolarity on taste and habits supports that a marketing strategy focused on those factors may have counterproductive effects, whereas the sense of alertness, mood improvement, and socialisation may be promising coffee attributes.

Third, food and beverage companies are increasingly interested in marketing heathy food products. There are studies that support that coffee is not unhealthy, and actually it may be beneficial for our health. These scientific findings are only partially reflected in consumers' coffee product image. Thus, in order to adequately market coffee with a health attribute there is a need to explore consumers' perception and on which health benefits attract consumers. Results support that the proposal of a health-claimed coffee on the market can be of interest among coffee consumers and non-consumers. Positively perceived claims may focus on coffee as a natural product. However, consumers tend to have controversial perceptions of coffee's effect on specific diseases. For example, some consumers think coffee is beneficial, and others detrimental to cardiovascular diseases. Consumers have a rather negative perception of caffeine, and caffeine is associated with coffee. Consumers may not be aware of the other natural coffee compounds. There is a need to define a communication and information strategy to inform consumers and align their image of coffee's health impact with evidence-based findings. The communication strategy may underline the latest research developments. To date, no advertisements or public policies have been promoted as regards health and coffee. The concern is to increase incorrect intakes of caffeine. However, this limits the launch of a new product that could have a significant market potential, pleases consumers' taste, and stimulates an array of positive emotions.

\subsection{Research Limitations}

The research may have some limitations. First, the survey was submitted to a convenience sample. This may limit the generalisability of the findings. However, the cross-country perspective provides a comparative viewpoint that strengthens the data analysed and the findings achieved. Future studies may further extend the multi-country approach. Second, the research focused on countries with a significant coffee tradition. Future research may include countries with limited coffee tradition to complement the current research. It may also focus on countries that have recently reported increased coffee consumption. Coffee consumers' and non-consumers' behaviour in these 
countries may be driven by a different set of motives and emotions. Third, the current research explored coffee consumers' emotions based on a validated scale to measure the emotions. There is a need to define a scale that fully captures coffee non-consumption perceptions. Food non-consumption behaviour is a research field that is under-investigated. Future research may aim at providing a methodological tool leading to scientifically-based results on non-coffee consumption emotions. Fourth, the current study adopted a well-established but single scale to measure emotions. Future studies may further expand the methodological approach using electrophysiology measures to understand consumers' emotions. Objective physiological measures, such as blood volume pulse, blood pressure, skin conductance, and heart rate, can complement subjective self-declared measures to fully capture consumers' emotions [60-64]. Finally, this research supports that consumers are interested in health-claimed coffee. However, an officially approved health-claim applied to coffee does not yet exist. The findings of the current explorative research can set the basis to test consumers' interest for future coffee product commercialisation based on specific health-oriented product attributes.

Author Contributions: Conceptualization, A.S. and C.A.; Methodology, A.S., C.A., and M.D.P.; Software, A.S. and C.A.; Validation, A.S.; Formal Analysis, A.S.; Investigation, C.A.; Data Curation, A.S. and C.A.; Writing-Original Draft Preparation, A.S. and M.D.P.; Writing-Review \& Editing, A.S.; Visualization, A.S.; Supervision, A.S. All authors have read and agreed to the published version of the manuscript.

Funding: This research received no external funding.

Conflicts of Interest: The authors declare no conflict of interest.

\section{Appendix A Health Effects of Coffee}

Coffee health positive and negative effects have been studied by various research centres, international organisations, and cross-national agencies. European Food Standard Agency, United States Food and Drug Agency, and International Agency for research on Cancer set guidelines in term of safe caffeine intake [65-67]. A moderate caffeine consumption quantity is between 300 and $400 \mathrm{mg} /$ day, and it does not have negative health effects. Only a high consumption (400-800 mg of caffeine in one sitting) has been associated with negative effects, such as nervousness, anxiety, aggressiveness, insomnia, tachycardia, and tremor [68]. Various studies have evaluated coffee impacts on different human organs, systems, and behaviours (see table below). Research studies support that coffee does not negatively impact cancer. The latest research supports that coffee consumption is linked with a lower risk of a number of causes of mortality, including a strong reduction in developing Type II diabetes, heart disease, strokes, and different types of cancer, such as prostate cancer, endometrial cancer, melanoma, non-melanoma skin cancer, and liver cancer [69]. Moderate consumption of coffee is also linked with lower death risk mainly due to digestive and circulatory disease. Similar evidence-based health-coffee associations are reported for people drinking regular decaffeinated coffee. This suggests that coffee's positive effects may be due to other compounds in coffee rather than caffeine itself [70].

Table A1. Main coffee health impacts.

\begin{tabular}{cc}
\hline $\begin{array}{c}\text { Caffeine has positive effects on concentration and alertness (with a recommended dose of } \\
75 \mathrm{mg} \text { ). It can increase both selective and prolonged attention by focusing on a stimulus or } \\
\text { an extended period, respectively [71]. There are no positive effects in terms of memory } \\
\text { improvement. However, Messina et al., 2015, detecting increased frontal lobe activity of } \\
\text { participants in a memory test after caffeine intake, found a positive relationship between } \\
\text { coffee and memory. }\end{array}$ \\
$\begin{array}{c}\text { Caffeine has a positive effect on pain by preventing or relieving symptoms. It has a direct } \\
\text { effect on migraines and headaches, acting as a vasoconstrictor on vessels that tend to } \\
\text { wigraine and } \\
\text { wependence }\end{array}$ & $\begin{array}{c}\text { widen } \text { Therefore, if taken with acetaminophen and aspirin, caffeine can positively } \\
\text { also have some negative aspects. Abstinence leads to a decrease in the vasoconstrictor } \\
\text { effect, thus generating headaches and leading to a physical dependence [72,73]. }\end{array}$ \\
\hline
\end{tabular}


Table A1. Cont.

\begin{tabular}{|c|c|}
\hline $\begin{array}{l}\text { Sleep and } \\
\text { Anxiety }\end{array}$ & $\begin{array}{l}\text { Although it depends on the sensitivity of each person [74], in addition to age, habits, } \\
\text { and the time of consumption [48], in general caffeine can lead to sleep and anxiety. It can } \\
\text { affect sleep in terms of quality and daytime sleepiness. It acts as a powerful stimulant, } \\
\text { but if consumed incorrectly, it can make people anxious, irritable, and agitated [75]. }\end{array}$ \\
\hline $\begin{array}{l}\text { Parkinson, } \\
\text { Alzheimer, Type } \\
\text { II diabetes }\end{array}$ & $\begin{array}{l}\text { Coffee intake can have positive effects on Parkinson's, Alzheimer's, and Type II diabetes. } \\
\text { Due to the inhibition of beta amyloid production and the positive effects on attention, } \\
\text { coffee reduces the possibilities of developing Alzheimer's from } 16 \% \text { to } 70 \% \text {. If Alzheimer's } \\
\text { disease is already present, coffee does not have the curative power [74]. Finally, those who } \\
\text { drink three to four coffees a day reduce by } 25 \% \text { the possibility of developing Type II } \\
\text { diabetes, compared to those who do not consume it or those who fewer than two cups a } \\
\text { day [76]. }\end{array}$ \\
\hline $\begin{array}{l}\text { Cardiovascular } \\
\text { system and } \\
\text { blood pressure }\end{array}$ & $\begin{array}{l}\text { Caffeine has an effect on all cardiovascular diseases. Where the only moderating variable is } \\
\text { smoking [46], the effects are positive in terms of the onset of the disease; also for } \\
\text { hypertension [22]. Moreover, recent studies support that there is a moderate increase ( } 22 \%) \\
\text { in the risk of cardiovascular disease when drinking large amounts of coffee (six or more } \\
\text { cups of coffee a day). Thus, the study sets a safety limit for coffee consumption: five cups } \\
\text { per day is the safety limit for the cardiovascular system [77]. }\end{array}$ \\
\hline
\end{tabular}

\section{References}

1. International Coffee Organization. Coffee Market Report: April 2020; International Coffee Organization: London, UK, 2020.

2. International Coffee Organization. Information Commissioner's Annual Report and Financial Statements 2018-19; International Coffee Organization: London, UK, 2018; Volume 139, ISBN 9781528614092.

3. International Coffee Organization. World Coffee Consumption; International Coffee Organization: London, UK, 2020.

4. Carvalho, N.B.; Minim, V.P.R.; Nascimento, M.; Vidigal, M.C.T.R.; Ferreira, M.A.M.; Gonçalves, A.C.A.; Minim, L.A. A discriminant function for validation of the cluster analysis and behavioral prediction of the coffee market. Food Res. Int. 2015, 77, 400-407. [CrossRef]

5. Mundel, J.; Huddleston, P.; Vodermeier, M. An exploratory study of consumers' perceptions: What are affordable luxuries? J. Retail. Consum. Serv. 2017, 35, 68-75. [CrossRef]

6. Blackout Coffee The Three Waves of Coffee. Available online: https://www.blackoutcoffee.com/blogs/thereading-room/the-three-waves-of-coffee (accessed on 17 October 2019).

7. Samoggia, A.; Riedel, B. Coffee consumption and purchasing behavior review: Insights for further research. Appetite 2018, 129, 70-81. [CrossRef] [PubMed]

8. Kanjanakorn, A.; Lee, J. Examining emotions and comparing the EsSense Profile ${ }^{\circledR}$ and the Coffee Drinking Experience in coffee drinkers in the natural environment. Food Qual. Prefer. 2017, 56, 69-79. [CrossRef]

9. Auffermann, K. From Brew Boomers to the Gourmet Generation: National Coffee Drinking Trends. 2017. Available online: https://nationalcoffee.blog/2017/03/28/from-basic-boomers-to-specialty-snowflakesnational-coffee-drinking-trends-2017/ (accessed on 18 December 2018).

10. Institute for Scientific Information on Coffee. The Good Things in Life: Coffee as Part of a Healthy Diet and Lifestyle. 2016. Available online: https:/www.coffeeandhealth.org/hcp-resources/reports-5/ (accessed on 20 November 2018).

11. Nawrot, P.; Jordan, S.; Eastwood, J.; Rotstein, J.; Hugenholtz, A.; Feeley, M. Effects of caffeine on human health. Food Addit. Contam. 2003, 20,1-30. [CrossRef] [PubMed]

12. Graham, K. Reasons for consumption and heavy caffeine use: Generalization of a model based on alcohol research. Addict. Behav. 1988, 13, 209-214. [CrossRef]

13. Ágoston, C.; Urbán, R.; Király, O.; Griffiths, M.D.; Rogers, P.J.; Demetrovics, Z. Why Do You Drink Caffeine? The Development of the Motives for Caffeine Consumption Questionnaire (MCCQ) and Its Relationship with Gender, Age and the Types of Caffeinated Beverages. Int. J. Ment. Health Addict. 2017, 16, 981-999. [CrossRef]

14. Morris, J. Coffee: A Global History; Reaktion Books: London, UK, 2018. 
15. Gómez-Corona, C.; Valentin, D. An experiential culture: A review on user, product, drinking and eating experiences in consumer research. Food Res. Int. 2019, 115, 328-337. [CrossRef]

16. Juodeikiene, G.; Zadeike, D.; Klupsaite, D.; Cernauskas, D.; Bartkiene, E.; Lele, V.; Steibliene, V.; Adomaitiene, V. Effects of emotional responses to certain foods on the prediction of consumer acceptance. Food Res. Int. 2018, 112, 361-368. [CrossRef]

17. Ares, G.; Gimenez, A.; Vidal, L.; Zhou, Y.; Krystallis, A.; Tsalis, G.; Symoneaux, R.; Cunha, L.M.; de Moura, A.P.; Claret, A.; et al. Do we all perceive food-related wellbeing in the same way? Results from an exploratory cross-cultural study. Food Qual. Prefer. 2016, 52, 62-73. [CrossRef]

18. Jaeger, S.R.; Lee, S.M.; Kim, K.O.; Chheang, S.L.; Jin, D.; Ares, G. Measurement of product emotions using emoji surveys: Case studies with tasted foods and beverages. Food Qual. Prefer. 2017, 62, 46-59. [CrossRef]

19. Bhumiratana, N.; Wolf, M.; Chambers IV, E.; Adhikari, K. Coffee Drinking and Emotions: Are There Key Sensory Drivers for Emotions? Beverages 2019, 5, 27. [CrossRef]

20. Labbe, D.; Ferrage, A.; Rytz, A.; Pace, J.; Martin, N. Pleasantness, emotions and perceptions induced by coffee beverage experience depend on the consumption motivation (hedonic or utilitarian). Food Qual. Prefer. 2015, 44, 56-61. [CrossRef]

21. Fenko, A.; Nicolaas, I.; Galetzka, M. Does attention to health labels predict a healthy food choice? An eye-tracking study. Food Qual. Prefer. 2018, 69, 57-65. [CrossRef]

22. Grosso, G.; Micek, A.; Godos, J.; Pajak, A.; Sciacca, S.; Bes-Rastrollo, M.; Galvano, F.; Martinez-Gonzalez, M.A. Long-term coffee consumption is associated with decreased incidence of new-onset hypertension: A dose-response meta-analysis. Nutrients 2017, 9, 890. [CrossRef]

23. Aguirre, J. Culture, health, gender and coffee drinking: A Costa Rican perspective. Br. Food J. 2016, 118, 150-163. [CrossRef]

24. Sousa, A.G.; Machado, L.M.M.; da Silva, E.F.; da Costa, T.H.M. Personal characteristics of coffee consumers and non-consumers, reasons and preferences for foods eaten with coffee among adults from the Federal District, Brazil. Food Sci. Technol. 2016, 36, 432-438. [CrossRef]

25. Samoggia, A.; Riedel, B. Consumers' perceptions of coffee health benefits and motives for coffee consumption and purchasing. Nutrients 2019, 11, 653. [CrossRef]

26. Wikoff, D.; Welsh, B.T.; Henderson, R.; Brorby, G.P.; Britt, J.; Myers, E.; Goldberger, J.; Lieberman, H.R.; O'Brien, C.; Peck, J.; et al. Systematic review of the potential adverse effects of caffeine consumption in healthy adults, pregnant women, adolescents, and children. Food Chem. Toxicol. 2017, 109, 585-648. [CrossRef]

27. Cherrier, H.; Black, I.R.; Lee, M. Intentional non-consumption for sustainability: Consumer resistance and/or anti-consumption? Eur. J. Mark. 2011, 45, 1757-1767. [CrossRef]

28. Arruda, A.C.; Minim, V.P.R.; Ferreira, M.A.M.; Minim, L.A.; da Silva, N.M.; Soares, C.F. Justificativas e motivações do consumo e não consumo de café. Ciência Tecnol. Aliment. 2009, 29, 754-763. [CrossRef]

29. Kaneko, D.; Toet, A.; Brouwer, A.M.; Kallen, V.; van Erp, J.B.F. Methods for evaluating emotions evoked by food experiences: A literature review. Front. Psychol. 2018, 9, 911. [CrossRef] [PubMed]

30. McNair, D.; Lorr, M.; Droppleman, L. McNair 1971; Educational and Industrial Testing Service: San Diego, CA, USA, 1971.

31. Lubin, B.; Zuckerman, M.; Hanson, P.G.; Armstrong, T.; Rinck, C.M.; Seever, M. Reliability and validity of the Multiple Affect Adjective Check List-Revised. J. Psychopathol. Behav. Assess. 1986, 8, 103-117. [CrossRef]

32. Steptoe, A.; Pollard, T.; Wardle, J. Development of a Measure of the Motives Underlying the Selection of Food: The Food Choice Questionnaire. Appetite 1995, 25, 267-284. [CrossRef] [PubMed]

33. Laros, F.J.M.; Steenkamp, J.B.E.M. Emotions in consumer behavior: A hierarchical approach. J. Bus. Res. 2005, 58, 1437-1445. [CrossRef]

34. Desmet, P.M.A.; Schifferstein, H.N.J. Sources of positive and negative emotions in food experience. Appetite 2008, 50, 290-301. [CrossRef]

35. King, S.C.; Meiselman, H.L.; Carr, B.T. Measuring emotions associated with foods in consumer testing. Food Qual. Prefer. 2010, 21, 1114-1116. [CrossRef]

36. Nestrud, M.A.; Meiselman, H.L.; King, S.C.; Lesher, L.L.; Cardello, A.V. Development of EsSense25, a shorter version of the EsSense Profile ${ }^{\circledR}$. Food Qual. Prefer. 2016, 48, 107-117. [CrossRef]

37. Spinelli, S.; Masi, C.; Dinnella, C.; Zoboli, G.P.; Monteleone, E. How does it make you feel? A new approach to measuring emotions in food product experience. Food Qual. Prefer. 2014, 37, 109-122. [CrossRef] 
38. Kelly, G.A. The Psychology of Personal Constructs: Volume Two: Clinical Diagnosis and Psychotherapy; Routledge: London, UK, 2003.

39. Schouteten, J.J.; De Steur, H.; De Pelsmaeker, S.; Lagast, S.; De Bourdeaudhuij, I.; Gellynck, X. An integrated method for the emotional conceptualization and sensory characterization of food products: The EmoSensory ${ }^{\circledR}$ Wheel. Food Res. Int. 2015, 78, 96-107. [CrossRef]

40. Ng, M.; Chaya, C.; Hort, J. Beyond liking: Comparing the measurement of emotional response using EsSense Profile and consumer defined check-all-that-apply methodologies. Food Qual. Prefer. 2013, 28, 193-205. [CrossRef]

41. Ares, G.; Bruzzone, F.; Vidal, L.; Cadena, R.S.; Giménez, A.; Pineau, B.; Hunter, D.C.; Paisley, A.G.; Jaeger, S.R. Evaluation of a rating-based variant of check-all-that-apply questions: Rate-all-that-apply (RATA). Food Qual. Prefer. 2014, 36, 87-95. [CrossRef]

42. Adams, J.; Williams, A.; Lancaster, B.; Foley, M. Advantages and Uses of Check-All-That-Apply Response Compared to Traditional Scaling of Attributes for Salty Snacks. In Proceedings of the 7th Pangborn Sensory Science Symposium, Minneapolis, MN, USA, 12-16 August 2007.

43. Bhumiratana, N.; Adhikari, K.; Chambers, E. The development of an emotion lexicon for the coffee drinking experience. Food Res. Int. 2014, 61, 83-92. [CrossRef]

44. Cardello, A.V.; Meiselman, H.L.; Schutz, H.G.; Craig, C.; Given, Z.; Lesher, L.L.; Eicher, S. Measuring emotional responses to foods and food names using questionnaires. Food Qual. Prefer. 2012, 24, 243-250. [CrossRef]

45. Thomson, D.M.H.; Crocker, C.; Marketo, C.G. Linking sensory characteristics to emotions: An example using dark chocolate. Food Qual. Prefer. 2010, 21, 1117-1125. [CrossRef]

46. Grosso, G.; Micek, A.; Godos, J.; Sciacca, S.; Pajak, A.; Martínez-González, M.A.; Giovannucci, E.L.; Galvano, F. Coffee consumption and risk of all-cause, cardiovascular, and cancer mortality in smokers and non-smokers: A dose-response meta-analysis. Eur. J. Epidemiol. 2016, 31, 1191-1205. [CrossRef]

47. Messina, G.; Zannella, C.; Monda, V.; Dato, A.; Liccardo, D.; De Blasio, S.; Valenzano, A.; Moscatelli, F.; Messina, A.; Cibelli, G.; et al. The beneficial effects of coffee in human nutrition. Biol. Med. 2015, 7, 1.

48. Clark, I.; Landolt, H.P. Coffee, caffeine, and sleep: A systematic review of epidemiological studies and randomized controlled trials. Sleep Med. Rev. 2017, 31, 70-78. [CrossRef]

49. Institute for scientific Information on Coffee. Coffee, Caffeine, Mood and Emotion. Available online: https://www.coffeeandhealth.org/topic-overview/coffee-caffeine-mood-and-emotion/ (accessed on 26 November 2018).

50. Bagozzi, R.P.; Yi, Y. On the evaluation of structural equation models. J. Acad. Mark. Sci. 1988, 16, 74-94. [CrossRef]

51. De Vellis, R.F. Scale Development: Theory and Applications; SAGE Publications, Inc.: Newbury Park, CA, USA, 1991; ISBN 978-0-8039-3775-8.

52. Fornell, C.; Larcker, D.F. Evaluating Structural Equation Models with Unobservable Variables and Measurement Error. J. Mark. Res. 1981, 18, 39. [CrossRef]

53. Corso, M.; Kalschne, D.; Benassi, M. Consumer's Attitude Regarding Soluble Coffee Enriched with Antioxidants. Beverages 2018, 4, 72. [CrossRef]

54. Spence, C.; Carvalho, F.M. The coffee drinking experience: Product extrinsic (atmospheric) influences on taste and choice. Food Qual. Prefer. 2020, 80, 103802. [CrossRef]

55. Nomisma. Coffee Monitor Nomisma-Datalytics: 260 Euro la Spesa Media Annua Degl Italiani per il Caffè; Nomisma: Bologna, Italy, 2018.

56. Ferreira, J.; Ferreira, C. Challenges and opportunities of new retail horizons in emerging markets: The case of a rising coffee culture in China. Bus. Horiz. 2018, 61, 783-796. [CrossRef]

57. Mahoney, C.R.; Giles, G.E.; Marriott, B.P.; Judelson, D.A.; Glickman, E.L.; Geiselman, P.J.; Lieberman, H.R. Intake of caffeine from all sources and reasons for use by college students. Clin. Nutr. 2019, 38, 668-675. [CrossRef]

58. Huntley, E.D.; Juliano, L.M. Caffeine Expectancy Questionnaire (CaffEQ): Construction, psychometric properties, and associations with caffeine use, caffeine dependence, and other related variables. Psychol. Assess. 2012, 24, 592-607. [CrossRef]

59. Nehlig, A. Is caffeine a cognitive enhancer? J. Alzheimer's Dis. 2010, 20 (Suppl. S1), S85-S94. [CrossRef] 
60. Szwoch, W. Emotion recognition using physiological signals. In Proceedings of the ACM International Conference Proceeding Series; IEEE: Piscataway, NJ, USA, 2013; pp. 556-561.

61. Kantono, K.; Hamid, N.; Shepherd, D.; Lin, Y.H.T.; Skiredj, S.; Carr, B.T. Emotional and electrophysiological measures correlate to flavour perception in the presence of music. Physiol. Behav. 2019, 199, 154-164. [CrossRef]

62. Xu, Y.; Hamid, N.; Shepherd, D.; Kantono, K.; Spence, C. Changes in flavour, emotion, and electrophysiological measurements when consuming chocolate ice cream in different eating environments. Food Qual. Prefer. 2019, 77, 191-205. [CrossRef]

63. Nijs, I.M.T.; Franken, I.H.A.; Muris, P. Food-related Stroop interference in obese and normal-weight individuals: Behavioral and electrophysiological indices. Eat. Behav. 2010, 11, 258-265. [CrossRef]

64. Alamir, M.A.; AlHares, A.; Hansen, K.L.; Elamer, A. The effect of age, gender and noise sensitivity on the liking of food in the presence of background noise. Food Qual. Prefer. 2020, 84, 103950. [CrossRef]

65. European Food Safety Authority. EFSA Explains Risk Assessment: Caffeine. EFSA Scientific Opinion Safety Caffeine 2015. Available online: https://www.efsa.europa.eu/en/corporate/pub/efsaexplainscaffeine150527 (accessed on 30 November 2018).

66. World Health Organization. IARC Monographs Evaluate Drinking Coffee, Maté, and Very Hot Beverages; World Health Organization: Geneva, Switzerland, 2016; pp. 2-3.

67. U.S. Food \& Drug Administration. Spilling the Beans: How Much Caffeine is Too Much? Available online: https://www.fda.gov/medical-devices/breast-implants/risks-and-complications-breast-implants (accessed on 3 March 2019).

68. European Food Safety Authority. Scientific Opinion on the safety of caffeine. EFSA J. 2015, 13, 4102.

69. Poole, R.; Kennedy, O.J.; Roderick, P.; Fallowfield, J.A.; Hayes, P.C.; Parkes, J. Coffee consumption and health: Umbrella review of meta-analyses of multiple health outcomes. BMJ 2017, 359, j5024. [CrossRef] [PubMed]

70. Park, S.Y.; Freedman, N.D.; Haiman, C.A.; Le Marchand, L.; Wilkens, L.R.; Setiawan, V.W. Association of coffee consumption with total and cause-specific mortality among nonwhite populations. Ann. Intern. Med. 2017, 167, 228-235. [CrossRef] [PubMed]

71. European Food Safety Authority. Scientific Opinion on the substantiation of health claims related to caffeine and increased fat oxidation leading to a reduction in body fat mass (ID 735, 1484), increased energy expenditure leading to a reduction in body weight (ID 1487), increased alert. EFSA J. 2011, 9, 1-29.

72. National Headache Foundation. Does Caffeine Trigger or Treat Headaches? Grants Regist. 2019. 2019. Available online: https://headaches.org/2019/02/24/does-caffeine-trigger-or-treat-headaches/ (accessed on 10 March 2019).

73. Espinosa Jovel, C.A.; Sobrino Mejía, F.E. Caffeine and headache: Specific remarks. Neurol. (Engl. Ed.) 2017, 32, 394-398. [CrossRef]

74. International Coffee Organization. Summary Report of the Dissemination Workshop on Coffee and Health; International Coffee Organization: London, UK, 2018.

75. Connolly, M. How to Tell If Coffee, Tea, or Other Forms of Caffeine Are Causing Anxious Feelings and/or Fueling Your Anxiety. Available online: https://www.psycom.net/anxiety-and-caffeine (accessed on 10 February 2020).

76. Institute for Scientific Information on Coffee. Coffee and Type 2 Diabetes: A Review of the Latest Research. 2018. Available online: https://www.coffeeandhealth.org/2018/11/coffee-and-type-2-diabetes-a-review-ofthe-latest-research/ (accessed on 3 December 2018).

77. Zhou, A.; Hyppönen, E. Long-term coffee consumption, caffeine metabolism genetics, and risk of cardiovascular disease: A prospective analysis of up to 347,077 individuals and 8368 cases. Am. J. Clin. Nutr. 2019, 109, 509-516. [CrossRef]

(C) 2020 by the authors. Licensee MDPI, Basel, Switzerland. This article is an open access article distributed under the terms and conditions of the Creative Commons Attribution (CC BY) license (http://creativecommons.org/licenses/by/4.0/). 